\title{
Practical Liability Issues of Information Technology Education: Internship and Consulting Engagements
}

\author{
Daniel A. Peak Michael J. O'Hara \\ dpeak@unomaha.edu mohara@unomaha.edu \\ University of Nebraska at Omaha, Omaha, NE 68182 USA
}

\begin{abstract}
This article examines university liability created by internship and consulting relationships. Business clients participating in outreach relationships formulate performance expectations based on perceptions of experience and / or qualifications. Clients assign tasks accordingly, and the university incurs liability that is conditioned by business clients' expectations. Substantial liability is related to unusually large and rare unfavorable outcomes in the outreach engagement, known as tail events. Tail events can significantly and negatively impact the client. Both the liability for and the probability of tail events increase as universities continue to expand business outreach activities. As internship and consulting engagements increase, the probability of a tail event also increases. The responsibilities of IT intern engagements and potential liability of the sponsoring university are analyzed. The university is the primary insurer for the client and indemnifies its representatives. All internship engagements should be formalized by written contract. An example contract is attached.
\end{abstract}

Keywords: University liability, Consulting, Internship, Intern, Information Technology, Contract, Outreach

\section{Introduction}

A student intern at a large communications company is given access to the company's data collection software and accidentally damages a critical systems software component, disrupting vital communications and customer services for several hours. Another intern at a small glass products manufacturer inadvertently pushes a piece of heavy equipment into a row sliding glass doors, costing the company nearly $\$ 60,000$ in ruined product and slowing deliveries. Still another, who is assigned to program critical system modules at a large petroleum firm, falters in his assignment and then conceals results of his failure until after the internship is over and he is gone, adversely affecting production and delivery schedules which result in losses exceeding $\$ 150,000$. These examples are of real events precipitated by student interns and observed by the authors--all which had significant adverse effects on the companies that employed the interns. Faculty consultants have been responsible for similar debacles.

Material published as part of this journal, either on-line or in print, is copyrighted by the publisher of Informing Science. Permission to make digital or paper copy of part or all of these works for personal or classroom use is granted without fee provided that the copies are not made or distributed for profit or commercial advantage AND that copies 1) bear this notice in full and 2) give the full citation on the first page. It is permissible to abstract these works so long as credit is given. To copy in all other cases or to republish or to post on a server or to redistribute to lists requires specific permission and payment of a fee. Contact

Editor@gise.org to request redistribution permission.
Sponsored internships and consulting engagements, particularly those that are related to Information Systems (IS) and Information Technology (IT), are dramatically increasing in importance and number throughout the United States. For example, the National Association of Colleges and Employers reported that 61 percent of their survey respondents offer summer student internship programs, after which nearly half of these interns were offered full-time positions (HR Focus 1997). Another research organization found that nearly 80 percent of the firms surveyed employed student interns throughout the year (Sweeney 1997). Still another reported that 98 percent use internships to screen for possible permanent employees (Frazee 1997). Of these same firms, 70 percent required new hires either to have had internships, or some other form of on-the-job-training. Actual work experience, which includes internships, was ranked second only to academic major as an interview screening criterion for college hires.

In addition, national trends indicate faculty internships and consultancies are also on the rise (Melinda Norris 1996). Directly correlating with that trend, most IS/IT employers in this area also offer opportunities to university faculty for updating and sharing of their skills and knowledge with industry (Sweeney 1997). These same employers frequently engage more experienced faculty as consultants in planning, research, and development efforts that are critical to their business (Peak and O’Hara 1998).

Although both internship and consulting engagements, also called co-operatives and fellowships, involve temporary relationships between a university representative and a 


\section{Liability Issues of Internship Engagements}

business, interning implies a different experience level than consulting. That is, interning generally involves a relatively inexperienced individual, while consulting features an experienced individual. Interns (a.k.a. "co-op students") can be either students or faculty, while consultants (a.k.a. "fellows") are almost always university faculty members.

\section{The Source of University Liability}

Businesses involved in university outreach relationships formulate business performance expectations based on how experienced or qualified they perceive the intern or consultant to be (Guttmann 1976). As a result, the university incurs liability that is conditioned by business clients' expectations. This article discusses the liability incurred by these university-sponsored relationships with the business community and gives practical examples, as well.

\section{General Expectations and Benefits Con- cerning Interns}

Interns are very different from consultants. An intern is expected to be a novice while a consultant is expected to be an expert, regardless of whether he/she holds student or faculty status (Kelley 1981; King 1995). Also, by definition, the internship exists so that the intern may acquire experience he/she is lacking (Melinda Norris 1996). According to the authors' University's guidelines, interning is a vehicle for individuals to acquire practical experience in an area where they have received academic training (IS\&T Internship Guidelines 1996; IS\&T Program Proposal 1995; UNO Undergraduate Catalog 1996; AACSB 1996). Using these concepts, the parties involved in an interning relationship will expect the student or faculty intern to be educated but to possess only general skills or knowledge about the tasks at hand. Consequently, the intern is expected to be relatively inexperienced in specific skills about those tasks.

The various parties participate in the outreach relationship for the benefits they receive. For instance, both student and faculty interns benefit because they increase their market value while they increase their business experience by working in a real-world environment (Balakrishnan, et al. 1995). Conversely, businesses that engage them benefit by obtaining the services of quality, relatively low-cost individuals (Kaplan, 1994). We will discuss these and other benefits in greater depth below.

\section{General Expectations and Benefits Con- cerning Consultants}

Faculty consultants can be either independent or universitysponsored. This article deals with the latter category. Parties involved in a consulting relationship typically expect a consultant to possess specific, significant and relevant skills 44 or knowledge about the tasks at hand (Guttmann 1976; Kaye 1994). Like interns, consultants who are simultaneously employed as university faculty also benefits from business experience gained working in a real-world environment. However, since consultants are already experienced, they often consult primarily for research and/or monetary compensation (George Norris 1996). Again, businesses that engage consultants benefit by obtaining the services of quality, relatively low-cost individuals, as well as numerous other benefits.

However, despite the many benefits of interning and consulting, relationships between a university's representatives and a client business incur liability to both parties. In this article, we focus on the liability incurred by a sponsoring university and its representatives who are involved in interning and consulting activities.

\section{The Concept of Liability and Insurance}

Liability is the legal responsibility of a liable party to compensate an injured party for loss suffered due to the liable party's acts or omissions (Weinstein 1988). Most people think of liability as resting entirely with a defendant. However, in situations where the plaintiff's acts also contribute to the harm, liability also may rest with the plaintiff. People who perceive liability exposure have a strong incentive to purchase insurance.

With a contract of insurance, the insurer bonds the insured's liability in exchange for payment of a policy premium. The insurer is obliged to provide protection to the insured, while the insured has the legal obligation to pay the premium and behave responsibly. Accordingly, the university provides protection for its representative who, renders services on behalf of the university. Therefore, the university may be held liable for acts of its interns and consultants. Liability is especially likely when the individual materially contributes to large losses (i.e., tail events), such as calamities caused to the client business' strategic planning process or to major changes in its IT infrastructure. The university and the client business both may share responsibility because both should have a degree of control over the intern.

\section{Relative Insurability of the Consultant}

We begin our discussion of university liability by examining the insurability of the university-affiliated IT consultant, which is a general case of the intern. Figure 1 represents the relative insurability of the university consultant. The vertical axis continuum shows that a business client expects the consultant to deliver an increasing level of performance, commensurate with an increasing level of knowledge perceived by the client. There two divisions of knowledge across this vertical continuum are: 1) Partial Knowledge, 
which begins from a low of Ignorance and leads up to the threshold of Competence, and continues through 2) Reason to Know, which begins inclusive of minimal Competence and culminates with (the theoretical) Full Knowledge.

Reason to know is a legal term that describes a region of knowledge that is capable of producing levels of performance all the way from competent to outstanding. The lowest range of reason to know, located at the middle of the vertical axis continuum, is the threshold of competent performance. Therefore, reaching that threshold of competence indicates that the consultant has attained minimal control or mastery of the knowledge in his/her field and is capable of exercising

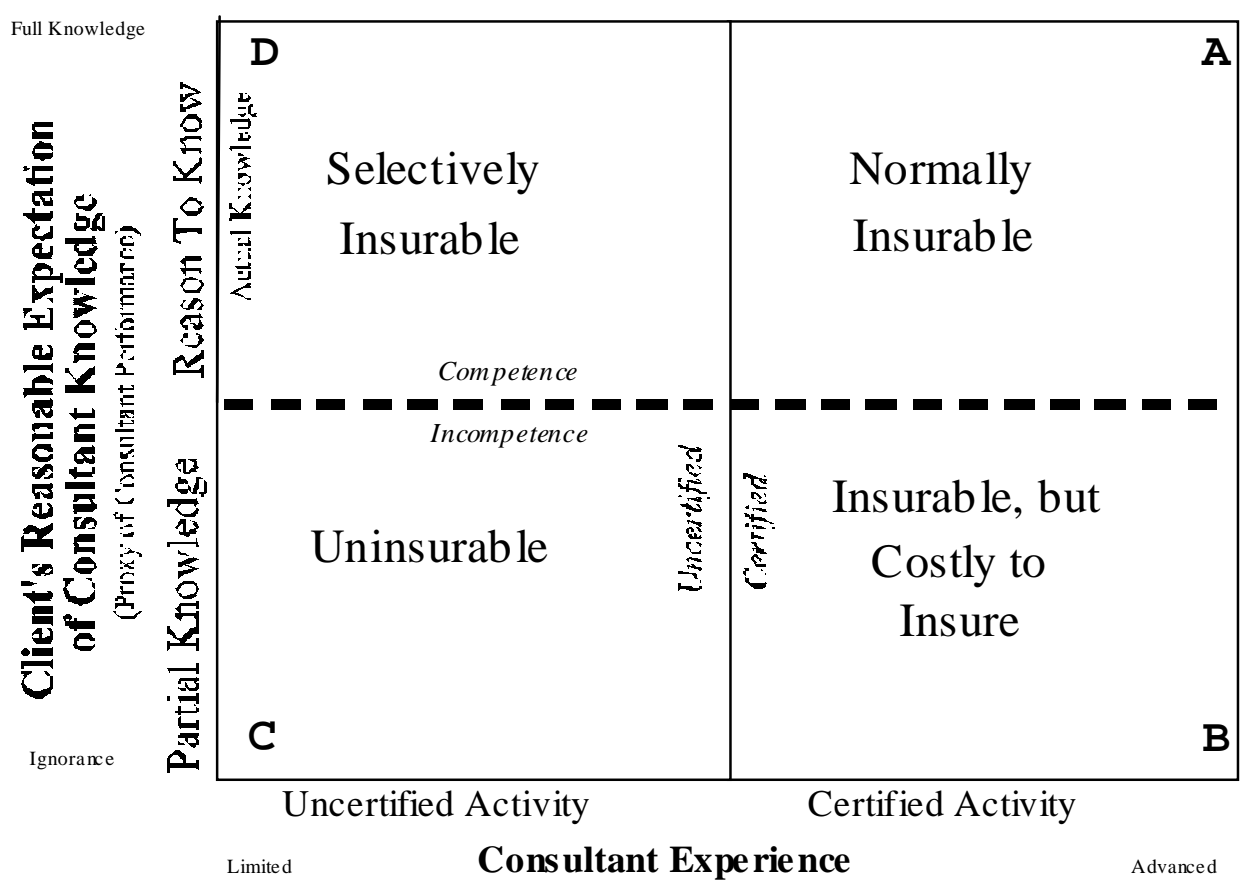

Figure - - Relative Insurability ofConsultants, Based on Certification and Competence (Peak and O' Hara 1998).
Although competence is a minimally acceptable subjective standard, it is certification that objectively assures the client, via a third-party appraisal, that the consultant has attained actual knowledge.

The liability test for competence/reason to know is substantially less rigorous than for actual knowledge, because reason to know may be established even if the consultant has never achieved actual knowledge. For example, merely having been exposed to knowledge (called "receipt of notice") can trigger liability by legally establishing that the consultant should possess the knowledge, even if he/she never acquired it. Using an analogy, prominent publication of a critical IT requirement in $M I S$ Quarterly can constitute receipt of notice for a subscriber, triggering liability. This surprising dilemma places sponsoring universities at risk for consultants who do not pursue continuous professional development.

The Figure 1 horizontal axis shows Consultant Experience relative to a continuum defined by standards of professional certification. The two divisions of this continuum are: 1 ) Uncertified Activity, which leads from the left to the threshold of certification, and 2) Certified Activity, which begins inclusive of certification and increases in experience level to the right.

Certification delineates a definitive, binary condition: either the consultant is certified or is not. At the threshold of certification, the consultant is certified as competent in, and having actual knowledge of, his/her field. it. Technically, reason to know is demonstrated by the acts, the words, and the circumstances surrounding the execution of the consultant's duties (Weinstein 1988). Legally, the university becomes liable when its consultant has acquired sufficient control to reach reason to know. Beyond mere competence, we show Actual Knowledge as the upper range of reason to know in Figure 1. It represents the high level of subjective consultant knowledge that is desired by a client. Unfortunately, people find it difficult to objectively verify precisely when the consultant acquires reason to know, and even harder to objectively recognize the attainment of subjective actual knowledge.

Certification, on the horizontal axis continuum, is an objective proxy, a signal, for actual knowledge. When the consultant is certified, i.e., graduated, he/she is recognized as having acquired actual knowledge at that point in time.
Historically, clients have shown preference for consultants whose knowledge is certified, either by governmental licensure, academic graduation, or by professional standard.

\section{What is Valued More: Actual Knowledge or Certification?}

In our experience, businesses value actual knowledge more highly than certification because actual knowledge is more closely linked with production. Certification is valued only as a proxy. It is also a typical prerequisite to a legal remedy, but since the remedy is not production it will be only reluctantly pursued. Nevertheless, a tail event caused by a consultant could induce a business client to invoke the remedy, which approximates the filing of an insurance claim. Recognizing the university as the de facto insurer, recall 


\section{Liability Issues of Internship Engagements}

Figure 1 divided relative consultant insurability into four quadrants, starting in the upper right with Quadrant A and reading clockwise through Quadrant D. The reader is referred to (Peak and O'Hara) for in-depth discussion of Figures 1 and 2.

\section{Relative Insurability of the Student Intern}

An extension of Figure 1, Figure 2 describes the insurability of student interns. The axes and quadrants of Figure 2

closely correspond to those of Figure 1. Figure 2 phases are

\section{Summary of Intern-incurred Liability}

Regardless of how many persons are involved in an internship engagement, liability flows towards all parties who knowingly and voluntarily control the outcomes. When an internship results in a significantly unfavorable outcome (e.g., a tail event), the apparent candidate for defendant is the intern, because, by definition, the intern is inexperienced. Realistically, however, the intern is the person least likely to hold primarily liable by law, since the intern is the person least likely to possess the requisite control. Under normal circumstances, the intern's university, the client, and the faculty supervisor, in that order, bear true primary liability. The university, in its role as advisor and teacher, and the client organization, in its role as employer and/or trainer, logically should have far greater knowledge than the intern should. In addition, internships traditionally feature university and/or client supervision, so both supervising parties should be prepared to intercept and mitigate unfavorable outcomes.

Supervising faculty, like competent faculty consultants, normally act from Quadrant A in Figure 1. Although they are normally insurable by the sponsoring university, Quadrant A individuals may likely experience personal primary liability, while Quadrant C students will not. In an internship, the faculty supervisor, in effect, absorbs potential intern liability and increases his/her own. However, this increased exposure is, in directly related to and therefore represent student grade levels (e.g., freshman, sophomore, junior, senior), where degree certification is granted following the final phase (phase four, for undergraduate students) of the student's university experience. The vertical axis in Figure 2 plots the continuum of the Client's Reasonable Expectation of Intern Performance, and also plots the student intern's knowledge, progressing from Ignorance to Full Knowledge. The horizontal axis plots continuum of the student Intern Experience, where the intern's control over personal performance progresses from Limited to Advanced. When the intern's experience reaches a mid-axis level, the intern receives certification, analogous to reaching reason to know. Now, Figure 2 differs from Figure 1 with respect to the vertical axis, where it displays the student's educational progression, culminating at mid-axis with the student's graduation (i.e., certification of attaining reason to know). turn, absorbed by a shield of contractual university affiliation--a shield that both protects the faculty member via university indemnification. Even if liable, the intern and the lone supervisor are distinctly unattractive as a defendants. Typically, they lack substantial economic resources to fund a court-ordered repayment. In addition, juries historically have sympathized with small litigants, so that plaintiffs seek defendants with deep pockets. Therefore, the law will tend to hold the university and/or the client liable for placement and consequences of an incompetent intern, in the absence of outrageous, irresponsible, or illegal acts by the intern.

Faculty interns merit additional discussion. Despite the liability shield, relatively speaking, faculty interns incur a greater primary liability than student interns do, and they are slightly more attractive as potential defendants. In Figure 2, a faculty intern occupying Quadrant C (i.e., uncertified and incompetent) will be exposed to greater liability than a Quadrant C student intern for a number of reasons. First, 
faculty have the more extensive education and perceived potential; their incompetence is less expected. Second, faculty interns are far more likely than student interns to be attractive defendants, in a monetary sense. Unlike most student interns, faculty interns will have an income and some accumulated assets. In addition, they are often are covered by insurance, either through their own policies or through university indemnification. Third, faculty enjoy an elevated social standing in the eyes of the community. In court, this elevated social standing may increase faculty liability. For example, if a jury recognizes that the faculty intern is operating in Quadrant C (i.e., uncertified and incompetent), instead of Quadrant A (i.e., certified expert), the jury may still impose the expectation that all faculty interns are uncertified experts acting from Quadrant D. Thus, the burden of liability is greater for the faculty intern than the student intern because the community views a faculty intern as a better risk.

\section{Why Businesses Engage Interns}

The inevitable question is: if businesses can expect interns to perform incompetently, then why would businesses engage them? Actually, there are many good reasons for businesses to engage interns. These same reasons apply to consultants, as well. Six reasons are that these individuals provide the business with:

- Temporary commitments

- Minimal cost of benefits

- Access to special, state-of-the-art skills

- Support for the hirer's perspective

- A fresh viewpoint

- An enhanced image to peer firms and to the community Business clients often seek out interns for temporary engagements, to serve as "temporary employees" with no longterm commitment on either side. Temporary engagements offer significant cost savings, which stem from reduced intern training needs (in knowledge areas acquired through university study) and near-zero employee benefit obligations. With interns, businesses may be able to quickly augment business operations, for example, to meet transient demand on the firm. The serviced transient demand can have several origins, for example: 1) a large, one time project (e.g., a Year 2000 project), 2) a transition period when additional in-house training is needed or additional staff is needed (e.g., introduction of a new software application), or 3) even a cyclical demand increase (e.g., software upgrades).

Interns may give employers access to special, current skills and knowledge, a primary strength of viable university internship programs (AACSB 1996; George Norris 1996). Skills possessed by an intern may be skills not available at the firm. For instance, interns may provide expertise in one skill area (e.g., systems development theory) in exchange for on-the-job training in another (e.g., systems development experience) (Balakrishnan, et al. 1995). Lastly, the skill may be in short supply (e.g., C++ skills), and the client may use interns as a tactic for filling skill demand.

According to the "new blood" theory, interns also may provide a fresh viewpoint on the business client's array of strengths, weaknesses, and opportunities (Gault 1996; Stroh, et al. 1996). Under this theory, the client seeks out interns as part of the in-house training program, when the intern is expected to "teach" as much or more than he/she learns. The "new blood" motive stems from the client's desire to introduce new ideas into the organization.

The client may wish to gain support or validate a personal perspective on a situation. In addition, the client may wish to appear proactive or to appear supportive of university. A friendly working relationship between the university, its representatives, and the business community contributes to mutual good will, benefiting all associated parties (AACSB 1996).

\section{Intern Performance Oversight}

A secondary benefit of the university-sponsored internship process is that it provides the business client with special oversight skills, including selection and monitoring services performed by a faculty supervisor. Faculty internships may require similar oversight by a department chair or an associate dean. Interns also will require oversight by the client's regular employees. Based on the information collected from each oversight process, the university can assess and adjust its programs, benefiting future students, interns, and clients.

\section{Internships Sponsored by Non- university Organizations}

The growing importance of internships is further evidenced by the emergence of non-university organizations that also sponsor internships. These organizations may function either as a clearinghouse or as a broker. An organization in our region, the Applied Information Management (AIM) Institute, functions as both.

AIM, a consortium of academic and business organizations, contacts businesses and encourages them to post IT internships. Currently, more than 80 businesses post intern positions with AIM. These businesses will review the applicant resumes provided by AIM and set up interviews with selected candidates. AIM also accepts unsolicited applications from individuals, recruits individuals, and conducts career fairs to fill the vacant internships (Mills 1997). All parties may search company and candidate listings at the AIM web site, located at http://www.omaha.org. 


\section{Liability Issues of Internship Engagements}

In economic terminology, AIM "makes a market" for interns. It acts as a clearinghouse, whose dimensions are defined by client specifications. It also acts as a broker, matching candidate qualifications with intern jobs. AIM accepts applications without pre-screening them. AIM merely facilitates the process, allowing the market itself to equalize demand and supply. The market is very active, with more than three-fourths of all internships eventually resulting in full-time employment. Academic postings and faculty internships are equally open (Sweeney 1997).

For example, one large company, which was not well structured to handle interns, so it seldom hired them. With interns, the company was legally obligated to address issues that include job security, training, seniority, benefits, and compensation--a process that was identical to that of its longer-term employees. Union issues also presented challenges. Currently, AIM performs a placement service for this company and pays the intern salary, while the company reimburses AIM and still benefits from IT interns. The company is freed from dealing with employment issues, while AIM opens doors for both the company to employ interns and for students who have no other universitysponsored internship opportunities. Some internship programs at our university work with AIM, as well.

From a liability perspective, AIM internships shield the universities because AIM places screening and supervising responsibility squarely at the feet of the employing business. However, if an AIM internship is coupled with an academic credit, then the university shares that liability. Just as with university-sponsored internships, AIM internships lower hiring risk to participating companies. AIM's director notes: "... (the interning of students) gives businesses a chance to see an employee without a long-term employment contract. It's hard to terminate employees these days. Internships usually don't have employment contracts, benefits, and so on. If the employer doesn't like the intern, there is no need for termination--the internship just ends (Sweeney 1997)."

AIM's interning role is a result of an imperfection in the regional job market. First, there is a deficit in the corporate community. Most corporations deal with interns on an ad hoc basis: they have not institutionalized their intern budgets, interviewing and hiring techniques, policies, or interactions with the originating colleges or universities. Nearly all internship activities are localized at the departmental level. Second, there is a deficit in the academic community. Most universities have not institutionalized their internship activities, either. Many professions do not require internships because supervising faculty must work without compensation or release time. However, internship policies are usually loosely localized at the college or university levels. Colleges of Education, because of licensure requirements, have fairly formalized procedures. However, in colleges frequented by IT students (e.g., engineering, IS, computer science), internship activities are often run at the departmental level. There, academic internships may be heavily dependent on the personal enthusiasm and work ethics of the faculty supervisor. In addition, locating an internship may depend on skills of the individual intern. Therefore, the university greatly contributes to the success of internships by institutionalizing them, as with many IS/IT degree programs. Techniques include allocating college credit, advisory interaction between faculty advisor and client supervisor, and through formal assessment procedures.

\section{Demand for IS/IT Internships}

The rising demand for competent IS/IT employees is fueling the growth of internships throughout the nation. The Chronicle of Higher Education (June 8, 1995) found that relative change in growth in bachelor's degrees in IS/ITrelated fields is actually negative. Fields experiencing negative growth in degrees awarded included mathematics (11 percent), engineering (-11 percent), engineering technology ( -30 percent), computer and information sciences ( -33 percent), and communications technology (-87 percent), compared with an average change across all fields of 17 percent.

\section{Why Internships Should not be Mandatory for all Students}

We believe that universities should avoid making internships mandatory for several reasons. First, the quality of the average internship opportunity is sure to decline as their number swells to contain the entire student body. The university should wish to secure only meaningful learning opportunities for its students, and mandatory internships will defeat this objective. Second, as the number grows, the quality of the average intern is likely to drop. The university's ability to secure internship opportunities will be directly influenced by business perceptions of intern quality. Third, some of the university's students may be minors who cannot participate in internships due to age, and cannot be contractually obligated. Fourth, university liability will increase significantly on three fronts: 1) interns placed in unsafe environments, 2) interns making errors, and 3) interns perceiving an "unreasonable" denial of an opportunity to graduate.

\section{University Control of Intern and Consultant Liability}

A university can control its liability exposure by minimizing the adverse effects of its interns and consultants who enjoy the shield of university indemnity. Since the sponsoring uni- 
versity typically bears primary liability for actions of all of these individuals, it should exercise priority control over its risk exposure and tail event avoidance in its outreach relationships. Hence, a well-managed university will proactively screen and supervise all its affiliated interns and consultants.

Each party to an outreach relationship has a degree of control over the relationship and therefore bears some potential liability within it. Poor communication as to assigned responsibility is often the root cause of error, loss, and liability. In managing its risk, the university would do well to alert all parties to their respective duties, controlling the engagement outcome. Each party experiences overlapping scopes of authority--a situation conducive to acrimonious strife. Legal resolution of conflicts embedded in such a complex environment is likely to poison the environment: a court trial is an unfavorable context for resolving these types of disputes and is likely to damage public relations. As a result, both the university and business client usually will try to keep negotiations low-key. Proscriptive front-end planning--where the university establishes enlightened policies, standards, and procedures--is a far better alternative than destructive tail-end litigation.

The university can manage and control the formal creation of sponsored relationships. At a minimum, a university should require outreach relationships to be formalized with written, signed "academic contracts." For a contract to be legally binding, each party to the contract must have reached the age of majority. With minors, the age of majority varies by State, the normal age is between 18 and 21 years of age. A separate set of problems will confront a university that is placing minors into internship relationships. The university's responsibilities (read liability) will increase and the university's ability to manage risk will decrease. Contracts can help reduce the impact of self-promoting promises by will not do, as well as what the business client may reasonably expect as to performance. All academic contracts should describe the general terms of the university/client relationship, the financial terms, and the time requirements, including the start and end dates, as well as business-hour restrictions. Each university should have a policy on academic contracts with the business community. The authors have included one a template IS/IT intern and consultant contract in Appendix A.

\section{Conclusion}

Responsible management of the university's internship and consulting risks requires an explicit, initial investment of institutional resources to establish polices and procedures appropriate for your institution and your business clients. It requires a commitment to continuous improvement, since all participants in the relationship (we hope) will be learning from the experience. It also requires proactive riskconsciousness from all involved faculty and administrators. We emphasize that this consciousness will not spontaneously occur; it must be the result of good outreach management (National Society for Experimental Education 1998). Included in "good outreach management" is assuring that internships offer a genuine opportunity for a challenging learning environment.

We believe that academic institutions should continue to expand their business outreach activities because of the inherent educational benefits. However, by promoting more internships and consultancies, the university simultaneously increases the probability of a tail event. A tail event could result in significant financial losses for all parties, but such an event could damage long-term relationships with business clients, as well. Consequently, the university has a responsibility to manage these relationships with care. Its survival may hang in the balance.

\section{References}

(June 8, 1995). Earned Degrees Conferred by U.S. Institutions, 1992-93. Chronicle of Higher Education , A37.

. (March 1997). Short-term vacancies. HR Focus 74.3, 7.

AACSB (American Academy of Collegiate Schools of Business) (March 1996). Report on the Task Force on Leadership, St. Louis, MO.

Balakrishnan, Anantaram; Stuart Brown, Duane Dunlap, and Robert Pahl. (Sept./Oct. 1995). "Interdisciplinary Industry-University Collaboration: Lessons Form an Operations Improvement Project." Interfaces 25.5, 12-41.

Board of Regents of the University of Nebraska (1996). The University of Nebraska at Omaha Undergraduate Catalog 1995-96, Omaha, NE: University of Nebraska at Omaha.

Frazee, Valerie. (Feb. 1997). Work/study programs give employers a sneak preview. Workforce 76.2, 19-20.

Gault, Robert F. (Oct. 1996). The CEO's PC-literacy Challenge. Management Review 85.10, 29-31.

Guttmann, Hans P. (1976). The International Consultant. New York, NY: McGraw-Hill Book Company.

Internship Guidelines for Students of the College of Information Science and Technology. internal document. University of Nebraska at Omaha, Omaha, Nebraska March, 1996.

Mills, Tim. (Fall 1997). AIM Wants to Help you Find a Job Online, PC Guide 3.3, 7.

National Society for Experiential Education, www.nsee.org.

Norris, George A. (May 1996). Caps, Gowns \& Insurance, Life Association News, 91.5, 102-112.

Norris, Melinda. (Oct. 6, 1996). UNO Dean Seeks to Mold Information Specialists: Omaha World Herald, 1M, 3M.

Peak, Daniel and Michael O’Hara. (1998). “Internship and Consulting Engagements in Information Technology: Management 


\section{Liability Issues of Internship Engagements}

of The University's Liability," Forthcoming in Journal of Management Issues.

Proposal for a Program in Information Science and Technology (March 1995). Internal document, Omaha, NE: University of Nebraska at Omaha.

Stroh, Linda K., Jeanne M Brett, Joseph P. Baumann, and Anne H. Reilly, Anne H. (June 1996). Agency Theory and Variable Pay

\section{Template Internship Academic Contract}

\section{General terms of the relationship}

This is an academic contract between the Intern/Consultant ), and the University ), and the Client ( ). Actions required of

the Client may be completed by the Client Supervisor ( ) .

The Intern/Consultant (circle one) has has not attained the age of majority. This internship (circle one) is is not for academic credit.

All parties agree that they are about to enter a complex relationship that may appear to be a hybrid relationship with academic and employment aspects. However, the parties further agree that the academic relationship shall be superior and shall not be compromised by any requirements of any simultaneous employment relationship. Further, the parties agree that those in the academic relationship will not unreasonably frustrate the objectives of any employment relationship that the Intern/Consultant may have running simultaneously with the internship/consultancy. (NOTE: in the remainder of the this document the terms "Intern" and "internship" will be used instead of "Intern/Consultant" and "internship/consultancy.")

2. Financial Terms and Time Requirements

The Client shall (a) pay the Errors and Omissions Policy premium (estimated premium \$ ); (b) pay the University \$ ;

and (c) compensate the Intern as follows (circle the letter for all that apply and fill in blanks were necessary): RELATIONSHIP

a. solely an academic relationship, no employment relationship

b. academic relationship coupled with employment relationship

c. solely an employment relationship, minimal academic relationship (i.e., no registration for academic credit).

COMPENSATION

d. zero dollars of compensation

e. dollars per hour of compensation

f. dollars per month of compensation

g. dollars per academic term of com-

pensation

h.

entire engagement

item- 8 payment obligations of the client.

dollars of compensation for the

there (circle one) are are not any

The University shall pay nothing to either the Client or to the Intern, unless required by a separate document attached to this academic contract (see below, item 8 , "Attached, Other Documents"). There (circle one) are are not any item- 8 payment obligations of the University.

The Intern shall pay (a) the normal costs associated with enrollment for academic credit, (b) the normal costs associated with travel to and from the Client's place of business and/or the agreed upon site for the internship, and (c) the normal costs born by the Client's employees in compliance with the Client's requirements (e.g., dress codes). The Intern shall have no other financial obligations springing from this academic contract unless explicitly required by a separate document attached to this academic contract (see below, item 8 ). There (circle one) are are not any item 8 payment obligations of the Intern.

This engagement shall start on the day of in the year

This engagement shall end on the day of in the year

This engagement corresponds with the academic term (s)

3. Description of responsibilities and duties:

Each party agrees to complete this academic contract and to complete all of item in good faith, and without arbitrariness or capriciousness.

a. of the University.

The University agrees to provide regularly scheduled off-site and on-site
Compensation Strategies. Academy of Management Journal, $39.3,751-767$

Sweeney, Robert. Personal Interview. (April 4, 1997). Peak, Daniel and O'Hara, Michael.

Weinstein, Martin. (1988). Summary of American Law. Rochester, NY: Lawyers Co-op. Pub. Co. academic supervision of the Intern's academic performance. This regularly scheduled academic supervision shall be scheduled by the Academic Supervisor in consultation with the Client and the Intern. No later than the start of the internship, the Academic Supervisor shall deliver to the Intern and to the Client a written schedule for such academic supervision. This schedule (circle one) is is not attached under item 8. However, all parties agree that the supervision provided by the Client should be more immediate and more significant in terms of immediate error detection than the academic supervision provided by the University.

The University agrees to obtain an Errors and Omissions Policy (or policies) covering the Intern and the Academic Supervisor in this engagement, to provide the Client, the Intern, and the Academic Supervisor with a copy of the Policy, and to bill the Client for the premium. This policy (circle one)

is is not attached under item 8 .

The University agrees to provide the Client with forms for evaluating the Intern at the scheduled conclusion of the internship. These forms (circle one) are are not attached under item 8 .

b. of the Client.

The Client agrees to provide a learning environment with genuine responsibilities appropriate for this Intern. The Client agrees to minimize irrelevant low-level office tasks (e.g., photocopying) assigned to the Intern. The Client agrees to provide the Intern with timely and significant on-site supervision of the Intern's performance, including timely and significant feedback on and guidance for the Intern's performance. At the scheduled conclusion of the internship, the Client agrees to provide the Intern, the Academic Supervisor, and the University $h$ a written evaluation of the Intern's performance. The Client's evaluation will be on forms supplied by the University.

\section{c. of the Intern.}

The Intern is expected to devote no less than

total hours

and no more than total hours working at (report to address)

to devote no less than as assigned by the Client. Additionally, the Intern is expected total hours and no more than

total hours working at the University as assigned by the Academic Supervisor.

The Intern is expected to honor the Client's work schedule requirements, dress codes, and other requirements for employees at this level of engagement. The Client's dress code is is not other than normal business dress. The Client's dress code is is not attached under item 8. Attached, Other Documents.

4. Description of Objectives and Deliverables

The objective of this academic contract is to provide the Intern with a realworld context for the application and refinement of existing knowledge and skills, as well as fostering the development of new knowledge and new skills appropriate to this Intern. The Client shall provide the Intern a work space including (circle all that apply) desk, telecommunications, computer, software, internet access, tools, and other Deliverables by the Client to the Intern (circle one) do do not include intellectual property, and ownership of such property (circle one) is is not provided for in Item 8 . The Client shall provide the University and the Intern a written evaluation on forms supplied by the University (see also item 3.b. above).

The Intern shall have two sets of deliverables: one for the Client and one for the University

The Intern's deliverables to the Client are. Deliverables by the Intern to the Client (circle one) do do not include intellectual property, and ownership of such property (circle one) is is not provided for in Item 8 .

The Intern's deliverables to the University are for academic evaluation and are

Deliverables by the Intern to the University (circle one) do do not include intellectua property, and ownership of such property (circle one) is is not provided for in Item

The University shall deliver to the Client (a) a copy of the Errors and Omissions Policy including a bill for the exact premium, (b) a written schedule for academic supervision, (c) an Intern trained to the level appropriate for this engagement, and (d) Deliverables by the

University to the Client (circle one) do do not include intellectual property, and 
ownership of such property (circle one) is is not provided for in Item 8 .

5. Adhesion terms

The are some terms which the University must have in all academic contexts. First among these is Academic Freedom. Additionally, the University is bound to its Charter and Bylaws, which are hereby incorporated by reference. (Copies may be obtained by contacting the University's Corporate Secretary at (

$$
) \text {. }
$$

6. Errors and Omissions Policy

Prior to the start of the Intern's engagement under this academic contract, the Academic Dean shall secure and the Business Client shall pay for an Errors and Omissions Policy (or policies) covering the actions of the Intern and the Academic Supervisor.

7. Liquidated Damages Clause

All parties agree that an internship is fraught with potential losses and that such losses typically are minimal but occasionally can be substantial. Substantial losses are particularly likely when the Intern is acting at the fringe of the Intern's knowledge base and when acting at the Client's site. Since the primary objective of this internship is educational, not commercial, the parties agree that each party will be responsible for his/her own attorneys' fees and will only be entitled to recover liquidated damages in an amount no greater than payments made by the recovering party pursuant to item 2 of this academic contract and not including any payments listed under item 8 .

8. Attached, Other Documents

The following documents are attached to this academic contract and made a part of this academic contract.

a. Contact Information Sheet (attached at the end of this form)

b.

c.

d.

e.

g.

k.

9. Choice of Law and Choice of Forum

This academic contract, and any necessary and related interpretation of the item 8 , shall be controlled by the law of the

State of

and conducted in the

and all lawsuits shall be commenced Court located in

County of the same State.

10. Signatures: This academic contract is not effective until all signatures have been affixed and until the student has complied with all other normal registration procedures. Each of the parties agrees to accept as valid a signature of any other party on a copy of this academic contract transmitted by a facsimile machine.

Intern or Consultant date
Business Client
Academic Supervisor $\square$
Academic Dean

${ }^{1}$ The Academic Supervisor of a Student Intern is the faculty member of record who is responsible for assigning the academic grade for the internship. The Academic Supervisor for a Faculty Intern or a Faculty Consultant is the faculty member's Department Chair. When the Department Chair is the Faculty Intern or Faculty Consultant, then the Dean is the Academic Supervisor.
Item 8 a. CONTACT INFORMATION SHEET

INTERN

Student Identification Number:

Academic Term of Registration YEAR

HOME ADDRESS

CITY STATE ZIP

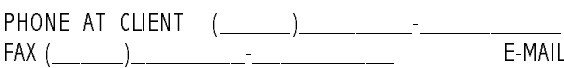

ACADEMIC SUPERVISOR

UNIVERSITY ADDRESS

UNIV. CITY STATE ZIP

UNIV FAX (__ _ _ _ _ _ UNIV E-MAIL

HOME ADDRESS

HOME CITY STATE ZIP

HOME PHONE (
HOME FAX (__ _ _ _ _ _ HOME E-MAIL

PHONE AT CLIENT (__
FAX AT CLIENT(_

CLIENT SUPERVISOR

BUSINESS ADDRESS

BUS CITY STATE ZIP

$\operatorname{BUSFAX}\left({ }_{-}\right) \ldots$ BUS E-MAIL

HOME ADDRESS

HOME CITY

STATE ZIP

HOME PHONE

HOME FAX

HOME E-MAIL 